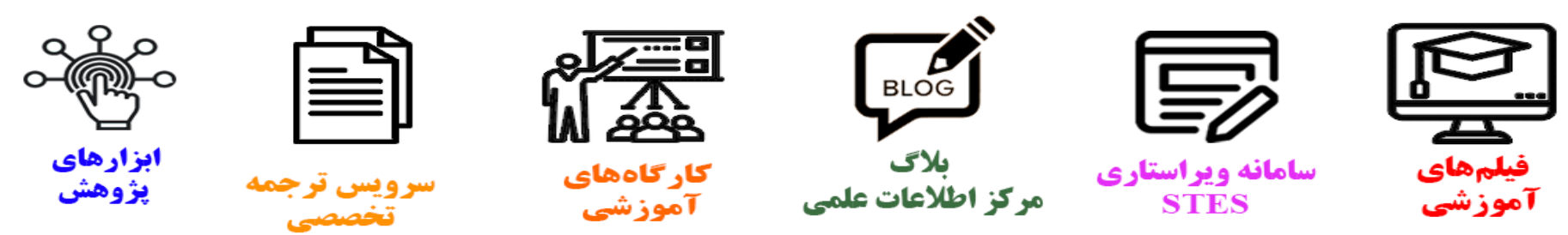

\title{
(c)
}

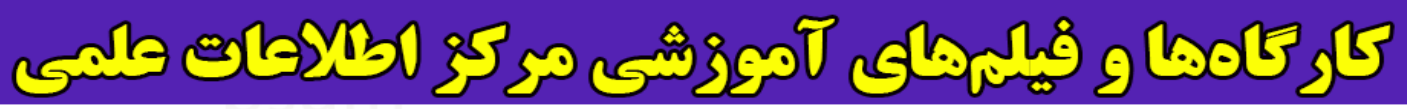
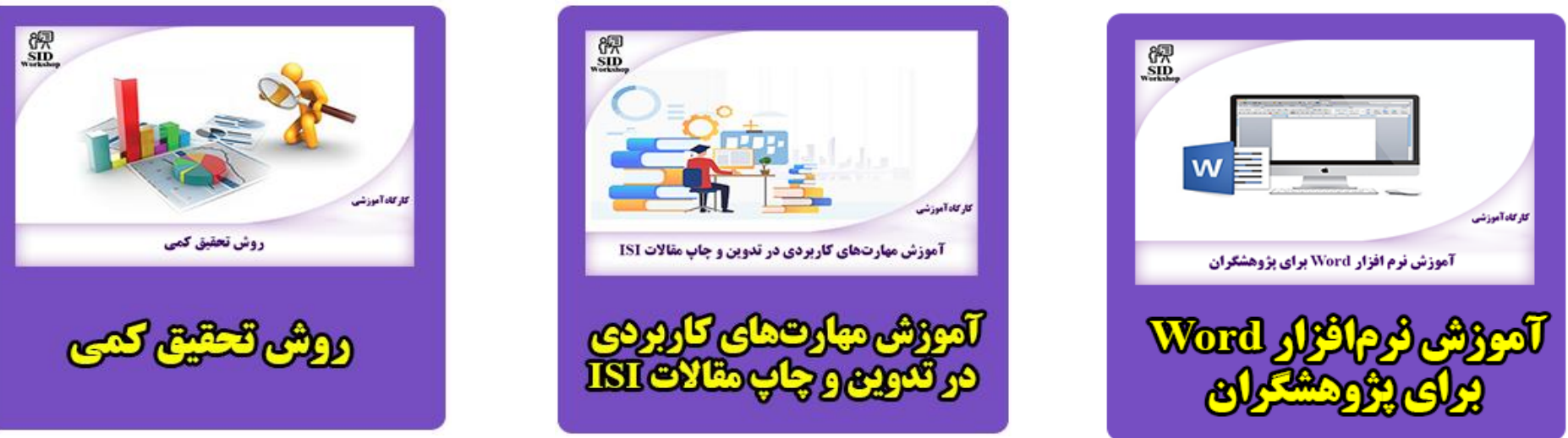


\title{
International Journal of Engineering
}

\section{Microstructure and Grain Refining Performance of a New Al-Ti-C Master Alloy}

\author{
M .R. Rahimipour, M. Momeni*, T. Naseri \\ Ceramic Department, Materials and Energy Research Center, Tehran, Iran
}

\section{$P A P E R \quad I N F O$}

Paper history:

Received 25 August 2012

Received in revised form 07 January 2013

Accepted 24 January 2013

\section{Keywords:}

Al-Ti-C Master Alloy

Grain Size

Solute Effect Theory

\begin{abstract}
$A B S T R$ A $C$ T
Control of microstructure features that affect the Al-Ti-C master alloys grain refining efficiency is leading to improve the aluminum grain refinement. This study has been done to find the solute effect theory to produce new Al-Ti-C master alloys to get more possibility to control these features. The produced master alloys were examined by scanning electron microscopy (SEM), energy-dispersive spectroscopy (EDS), and X-ray diffraction (XRD); also, the influence of them on pure aluminum was studied. Produced Al-6Ti-1C master alloy contained Ti and TiC particles in the aluminum matrix and Al-4Ti-1C contained TiC particles in the aluminum matrix. As the result, the produced Al-6Ti-1C master alloy is a more efficient grain refiner for pure aluminum as compared to the Al-4Ti-1C. This confirms the influence of $\mathrm{Ti}$ particles for grain refinement. The results showed that $\mathrm{Al}-6 \mathrm{Ti}-1 \mathrm{C}$ master alloy had maximum grain refining performance with 2 minutes holding time, at $983{ }^{\circ} \mathrm{K}$ temperature , and $1 \%$ wt master alloy addition. Finally, a new Al-Ti-C master alloy with excellent refinement has been prepared successfully.
\end{abstract}

doi: 10.5829/idosi.ije.2013.26.07a.04

\section{INTRODUCTION}

Microstructure modification of manufactured parts is widely considered in the aluminum industry to improve mechanical properties $[1,2]$. The most effective way for this purpose is adding master alloy to molten aluminum. Today, Al-Ti-C master alloy is widely used to improve physical and mechanical properties of products in aluminum industries. In these industries, it is needed to increase the grain refining efficiency of Al-Ti-C master alloys. According to industry needs, researchers are looking for Al-Ti-C master alloy production with maximum grain refinement performance [3-6]. In this regard, the influence of rare earth elements addition such as $\mathrm{Sr}$ to Al-Ti-C master alloy for increasing grain refinement efficiency [7, 8] as well as grain refining prperties of alloying elements such as $\mathrm{Zr}$ was studied [9]. Much research has been done on the production methods of Al-Ti-C master alloys [10, 11]; for instance, Doheim, et al. [12] produced Al-Ti-C master alloy by reacting a compacted mixture of titanium-bearing salts $\left(\mathrm{K}_{2} \mathrm{TiF}_{6}\right)$ and graphite with molten aluminum. Several studies focused on the ratio of $\mathrm{Ti} / \mathrm{C}$ to increase grain refining efficiency $[13,14]$. Effective microstructure

*Corresponding Author Email: mahboubeh.momeni@gmail.com (M. Momeni) features of Al-Ti-C master alloy on refining efficiency include chemical composition of particles in the aluminum matrix, quantity of particles, particle size and distribution, and particle morphology. Researchers try to modify production techniques and processes to control these parameters for grain refining [3, 6, 11, 15-19], but control of all microstructural features that have influence on Al-Ti-C grain refinement efficiency have not been possible up to now.

Various theories have been proposed for Al-Ti-C master alloy grain refining mechanism. Solute effect theory is the most reliable one [20]. $\mathrm{TiC}$ or $\mathrm{Al}_{3} \mathrm{Ti}$ particles or both of them, which caused grain refinement, exist in the Al-Ti-C master alloys that have been produced up to now [20]. When Al-Ti-C master alloy is added to molten aluminum, TiC particles act as heterogeneous nucleation sites [11]. According to the solute effect theory, $\mathrm{Ti}$ is formed from $\mathrm{Al}_{3} \mathrm{Ti}$ particles during a peritectic reaction in molten aluminum. A certain amount of $\mathrm{Ti}$ particles, which dissolve in $\mathrm{Al}$ melt, act as barrier for growth of $\alpha$-Al on the TiC nucleant substrate. Grain refining caused by titanium additions is caused by the titanium as a solute [20].

The purpose of this research is production of a new Al-Ti-C master alloy with more possibility for controlling the microstructural features, with the end result of getting more grain refining efficiency. 


\section{EXPERIMENTAL}

The Al-Ti-C master alloy was prepared with powder metallurgy method from compound containing commercially pure $\mathrm{Al}, \mathrm{Ti}$, and $\mathrm{TiC}$ powders. The average particle size of Al powder was $400 \mu \mathrm{m}$, while $\mathrm{Ti}$ and $\mathrm{TiC}$ powder particle sizes ranged from 1 to $5 \mu \mathrm{m}$. Pure $\mathrm{Al}(99.98 \%)$ was used to confirm the grain refining performance of the Al-Ti-C grain refiners. In this study, two types of Al-Ti-C master alloy were produced, one comprising of $5 \%$ wt $\mathrm{TiC}, 2 \%$ wt $\mathrm{Ti}$ and $93 \%$ wt $\mathrm{Al}$ powders, and the other $5 \%$ wt $\mathrm{TiC}$ and $95 \%$ wt $\mathrm{Al}$ powders. Both of them were ball milled for 30 minutes. Then, they were cold pressed and hot extruded. Hot extrusion temperature was $693 \mathrm{~K}$. Rod-shaped Al-6Ti1C and Al-4Ti-1C master alloys with $11 \mathrm{~mm}$ in diameter were prepared by this technique. The master alloys were examined using scanning electron microscopy (SEM), energy-dispersive spectroscopy (EDS), and X-ray diffraction (XRD). To compare grain refinement of master alloys, the master alloys were added to the commercially pure $\mathrm{Al}$ melts at $983^{\circ} \mathrm{K}$ and 2 minutes holding time. Then, 0.25 to $1.25 \%$ of $\mathrm{Al}-6 \mathrm{Ti}-$ $1 \mathrm{C}$ was added to the $\mathrm{Al}$ melts at $983^{\circ} \mathrm{K}$ and 2 minutes holding time. For holding time investigation, $1 \% \mathrm{Al}-$ $6 \mathrm{Ti}-1 \mathrm{C}$ was added to the $\mathrm{Al}$ melt at $983^{\circ} \mathrm{K}$ ranging from 30 seconds to 30 minutes. The effect of temperature was studied by adding $1 \% \mathrm{Al}-6 \mathrm{Ti}-1 \mathrm{C}$ to the $\mathrm{Al}$ melt in a range of $973 \mathrm{~K}$ to $993 \mathrm{~K}$. All samples were poured into a sand mold (20 mm in diameter and $150 \mathrm{~mm}$ in height). The samples were cut at a distance of $75 \mathrm{~mm}$ from the bottom surface, and polished. A reagent of $60 \% \mathrm{HCl}$, $30 \% \mathrm{HNO}_{3}, 5 \% \mathrm{HF}$, and $5 \% \mathrm{H}_{2} \mathrm{O}$ was used for etching the samples. The sectioned plane was prepared for macrostructure study with a digital camera and grain size measurements with the line-intercept method. Finally, the Vickers microhardness test was carried out on the pure $\mathrm{Al}$ samples refined by the $\mathrm{Al}-6 \mathrm{Ti}-1 \mathrm{C}$ refiner.

\section{RESULTS AND DISCUSSIONS}

Figure 1 shows the SEM microstructure of the Al-6Ti-1C master alloy. It can be seen that $\mathrm{Ti}$ and $\mathrm{TiC}$ particles are dispersed in the aluminum matrix. Figure 2 shows these two particles in higher magnification. The block-like particles are $\mathrm{TiC}$ and the spongy like particles are $\mathrm{Ti}$ as confirmed by using an energy-dispersive $\mathrm{X}$-ray micro analyzer (EDX) illustrated in Figures 3 and 4. Figure 5 shows Al-6Ti-1C master alloy XRD analysis.

According to the solute effect theory, $\mathrm{Al}_{3} \mathrm{Ti}$ particles are important in the grain refining process indirectly. Solute Ti with grain growth restricting property plays a direct role in the grain refining process $[4,20]$. So, it can be predicted that role of Ti particles is the same as
$\mathrm{Al}_{3}$ Ti particles in $\mathrm{Al}-\mathrm{Ti}-\mathrm{C}$ master alloy grain refinement performance.

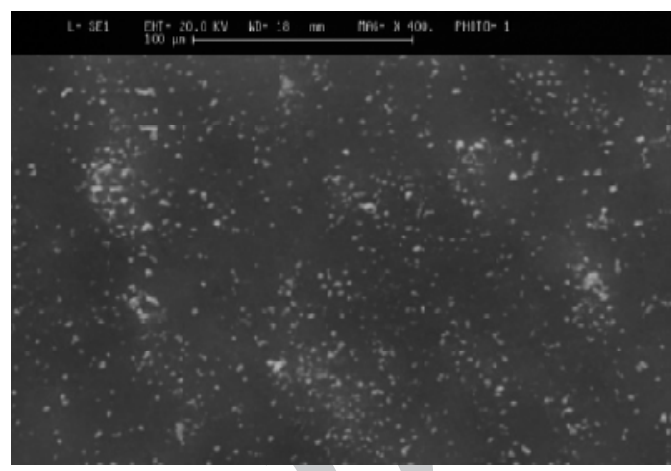

Figure 1. SEM image of Al-6Ti-1C master alloy at 400X.

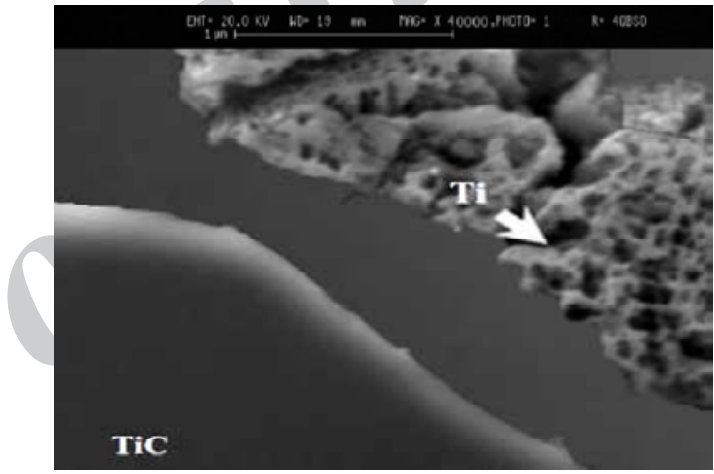

Figure 2. SEM image of Al-6Ti-1C master alloy at 40000X.

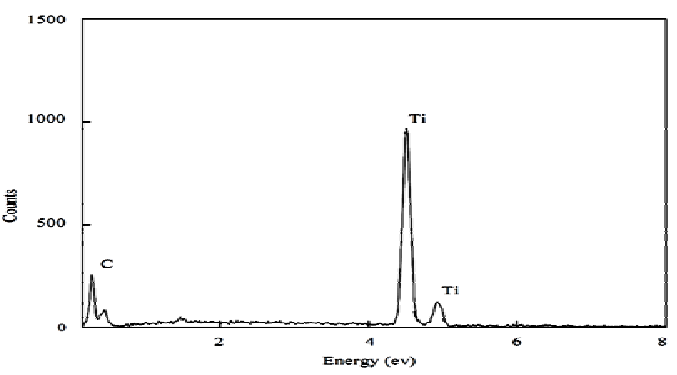

Figure 3. EDS analysis of block like particles in Al-6Ti-1C master alloy.

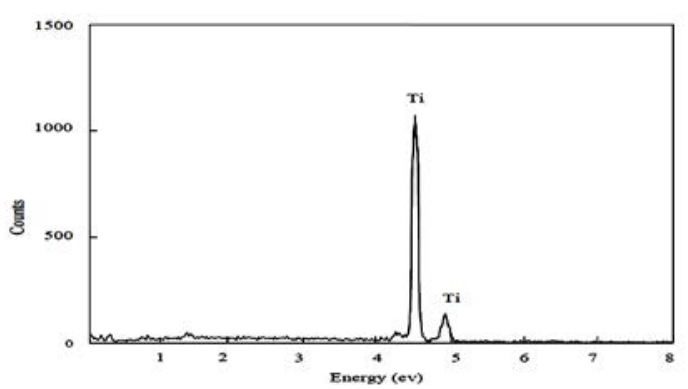

Figure 4. EDS analysis of spongy like particles in Al-6Ti-1C master alloy. 


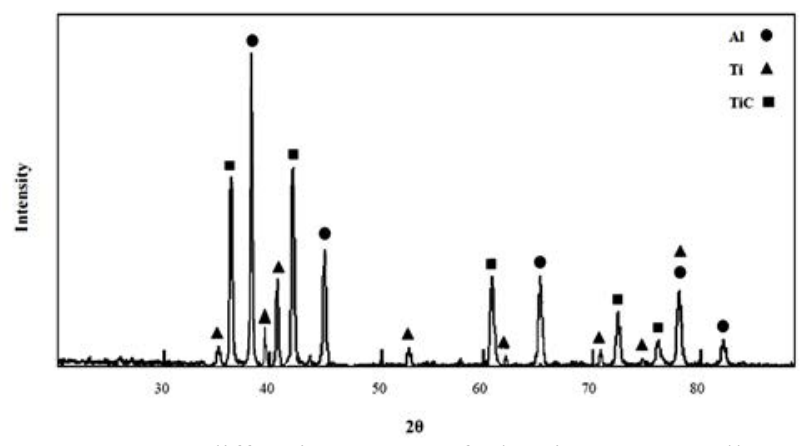

Figure 5. X-ray diffraction pattern of Al-6Ti-1C master alloy.

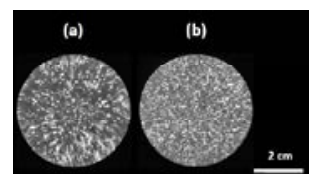

Figure 6. Macrostucture of commercial pure aluminum, (a) refined with Al-4Ti-1C, (b) refined with Al-6Ti-1C .

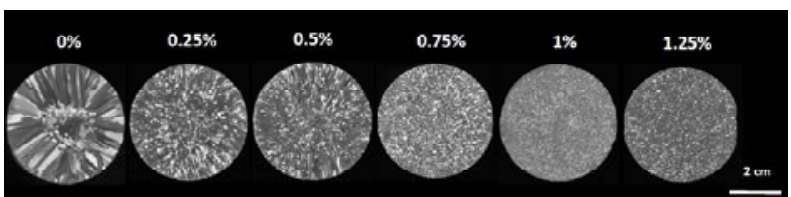

Figure 7. Macrostucture of commercial pure aluminum refined with different addition level of Al-6Ti-1C master alloy.

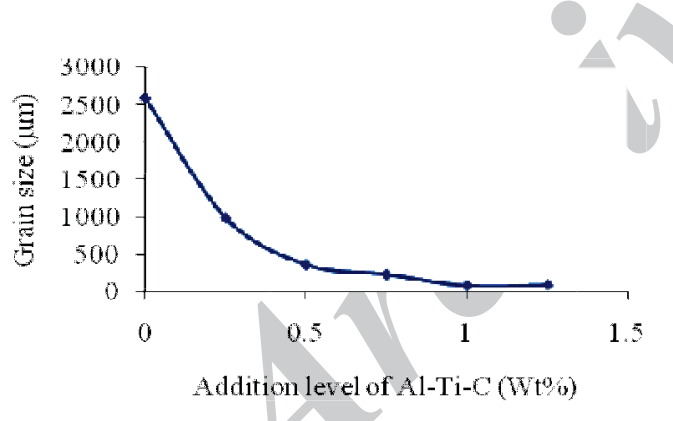

Figure 8. Addition level of the produced Al-6Ti-1C master alloy versus the grain size of the refined aluminum.

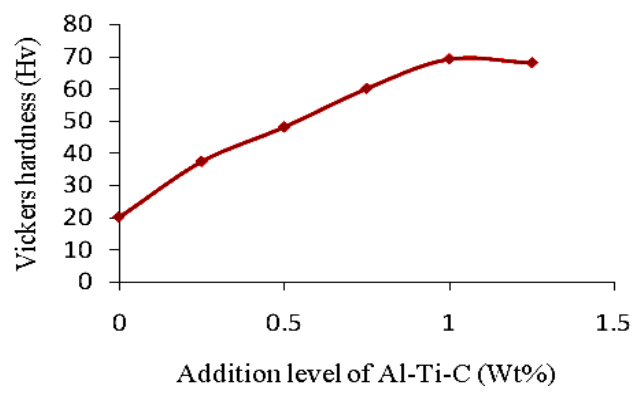

Figure 9. Addition level of the produced Al-6Ti-1C master alloy versus microhardness of the refined aluminum.
To prove the effectiveness of $\mathrm{Ti}$ particles in Al-Ti-C master alloy grain refining, $0.75 \%$ wt $\mathrm{Al}-6 \mathrm{Ti}-1 \mathrm{C}$ master alloy with Ti particles and $0.75 \%$ wt Al-4Ti-1C master alloy without Ti particles were added to pure aluminum melt at $983^{\circ} \mathrm{K}$ and 2 min holding time separately. Figure 6 shows that the grain size of aluminum refined by A1$6 \mathrm{Ti}-1 \mathrm{C}(200 \mu \mathrm{m}$ in average $)$ is much lower than that of A1-4Ti-1C $(500 \mu \mathrm{m}$ in average). The specimen refined by A1-4Ti-1C displays a mixture of coarse columnar and equiaxed grains, while the specimen refined by A16Ti-1C displays fine equiaxed grains rather than the columnar grains. This difference confirms the effect of Ti particles in grain refining mechanism.

The infulence of Al-Ti-C master alloy addition level on commercially pure aluminum grain refinement was studied. A series of experiments were carried out in a range of $0.25 \%$ to $1.25 \%$ wt addition levels at constant temperature of $983 \mathrm{~K}$ and 2 minutes holding time. Figure 7 shows the macrostructure of commercially pure aluminum refined with different addition levels of Al-6Ti-1C master alloy. Figures 8 and 9 illustrate the addition level versus the grain size and microhardness of the refined aluminum respectively. The Minimum grain size and maximum hardness reached at $1 \%$ addition level. It is shown that in the solidified structures, $\alpha$-Al crystals are partially columnar grains and most of fine equiaxed grains. Also, with the increase of the refiner addition levels, the $\alpha$-Al mean grain sizes of pure Al samples become gradually finer. It shows that the grain size decreases with increasing $\mathrm{Ti}$ weight ratio. This might be because of increasing in the nucleating ratio with the increase of the $\mathrm{Ti}$ content according to the solute effect theory and TiC particles increment as nucleation sites $[4,20]$. When $1 \%$ grain refiner is added, the average grain size reaches its minimum. But further increase in the addition level of grain refiner shows no significant improvement in grain refining efficiency. Also it shows the mechanical properties of commercial pure aluminum increased with the decreasing the average grain size.

The influence of holding time on grain refinement of commercially pure aluminum was studied in a range of 30 seconds to 30 minutes. The experiments were carried out at $983 \mathrm{~K}$ and $1 \%$ Al-6Ti-1C master alloy addition level with holding times of 30 seconds, 2, 5, 20 and 30 minutes. Figure 10 shows the macrostructures of the refined commercially pure aluminum. Figures 11 and 12 illustrate the effect of holding time on grain size and microhardness of the refined commercially pure aluminum, respectively. The minimum grain size and maximum hardness reached at 2 minutes holding time. At the start of reaction, the grain size decreases sharply with the holding time and then increases slowly. This means that the Al-Ti-C grain refiner fades with the increase of holding time. It can be concluded that the holding time contributes to dissolution and settling of 
TiC particles, whether they are dissolving in the melt or being precipitated or agglomerated.

The effect of temperature on the grain refining efficiency of commercially pure aluminum was studied from 973 to $993 \mathrm{~K}$ with 20 degrees increments at constant holding time of 2 minutes and $1 \%$ master alloy addition level. Figure 13 shows the macrostructures of the refined commercially pure aluminum using Al-6Ti$1 \mathrm{C}$ master alloys at different temperatures. The grain size decreases slightly with the increase of pouring temperature until reaching a minimum value of grain size at $993 \mathrm{~K}$. Then, the grain size increases noticeably with pouring temperature. It is found that when the melt temperature is $983 \mathrm{~K}$, the dissolved Ti content providing a high grain growth restricting parameter value, which assures the number of potent $\mathrm{TiC}$ nuclei in the $\mathrm{Al}$ melt, mean grain sizes of $\alpha-\mathrm{Al}$ crystals are refined to an optimal and stable value, so optimal temperature for the Al-Ti-C master alloy produced in this study is $983^{\circ} \mathrm{K}$. This is lower than those in other reports, which might be caused by the time needed for the $\mathrm{Al}_{3} \mathrm{Ti}$ particles to dissolve into the $\mathrm{Al}$ melt in other $\mathrm{Al}-\mathrm{Ti}-\mathrm{C}$ master alloys that have $\mathrm{Al}_{3} \mathrm{Ti}$ particles rather than $\mathrm{Ti}$ particles. At higher melt temperatures, the grain refining performance fade progressively. This is caused by instability of $\mathrm{TiC}$ particles and decreasing influence of the $\mathrm{TiC}$ nucleus in $\mathrm{Al}$ melt at those higher melt temperatures. It is considered that the effective nucleation temperature of the $\mathrm{TiC}$ particles in the $\mathrm{Al}$ matrix is about $938 \mathrm{~K}$ according to the temperature dependence of the phase equilibria on the Al-Ti-C diagram [20]. Figures 14 and 15 illustrate the effect of pouring temperature on grain size and microhardness of the refined commercially pure aluminum respectively.

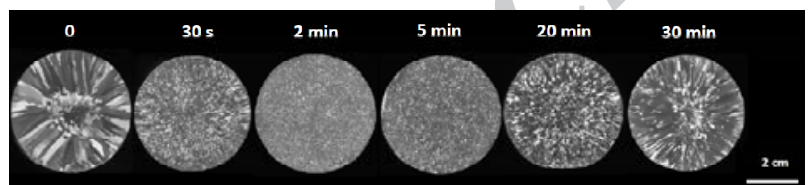

Figure 10. Macrostructure of the refined commercially pure aluminum using Al-6Ti-1C master alloy at different holding times.

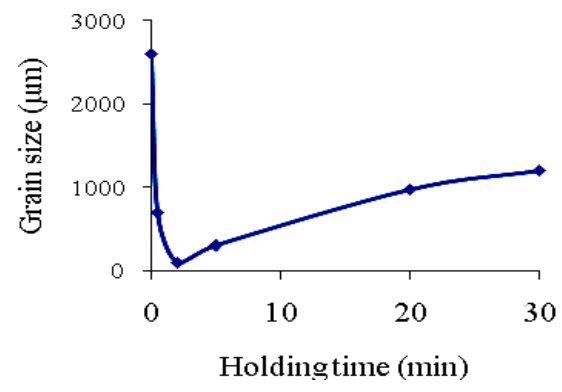

Figure 11. Effect of holding time on the grain size of the refined commercially pure aluminum using Al-6Ti-1C.

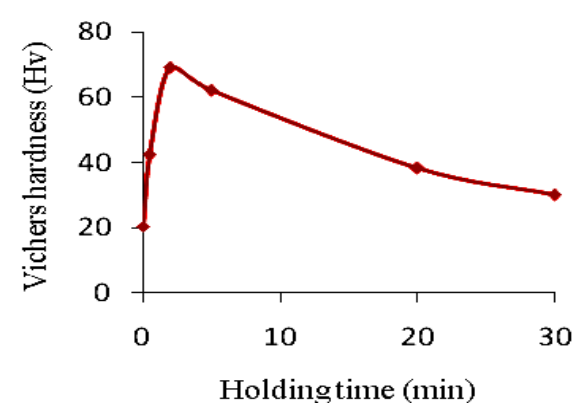

Figure 12. Effect of holding time on microhardness of the refined commercially pure aluminum usingAl-6Ti-1C.

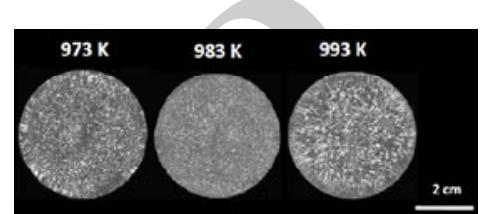

Figure 13. Macrostructure of the refined commercially pure aluminum using $\mathrm{Al}-6 \mathrm{Ti}-1 \mathrm{C}$ master alloys at different pouring temperatures.

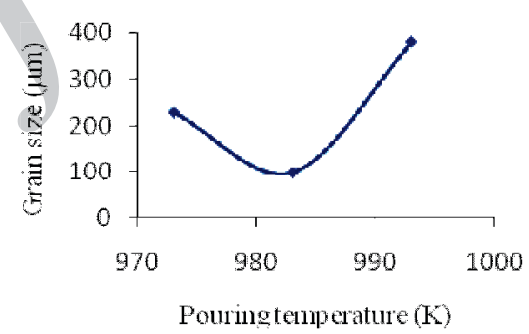

Figure 14. Effect of pouring temperature on the grain size of the refined commercially pure aluminum using Al-6Ti-1C.

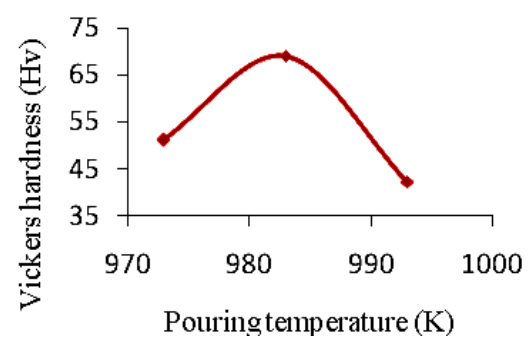

Figure 15. Pouring temperature affect on the microhardness of the refined commercially pure aluminum using Al-6Ti-1C.

Minimum grain size of $90 \mu \mathrm{m}$ and maximum hardness $70 \mathrm{Hv}$ was reached at $983 \mathrm{~K}$. Comparing these results with other researchers' results [4, 5, 11, 12, 17], it has been observed that with the addition of smaller amounts of produced Al-Ti-C master alloy to pure aluminum can achieve the highest refining efficiency 
ever reported. This production method is very simple and Industrial scale production costs are lower than current methods $[11,12]$. This method can be used to produce Al-Ti-C master alloys with different microstructures, so $\mathrm{Ti}$ and $\mathrm{TiC}$ particles can be present with appropriate type of morphology that have the best grain refining efficiency for each of aluminum alloys. For the first time it has been shown that Ti particles within aluminum matrix in our Al-Ti-C master alloys act as efficient grain refiners.

\section{CONCLUSION}

The aim of current study is to find a new approach in Al-Ti-C master alloys production that provides more control in effective microstructure parameters for grain refining efficiency.

* A new Al-Ti-C master alloy was produced successfully.

* Produced Al-6Ti-1C master alloy contained Ti and $\mathrm{TiC}$ particles in the aluminum matrix and Al-4Ti-1C contained $\mathrm{TiC}$ particles in the aluminum matrix that $\mathrm{Al}-6 \mathrm{Ti}-1 \mathrm{C}$ is a more efficient grain refiner for pure aluminum compared with the Al-4Ti-1C one. For the first time it has been shown that Ti particles within aluminum matrix in Al-Ti-C master alloys act as efficient grain refiners, so $\mathrm{Ti}$ and $\mathrm{TiC}$ were detected as effective phases in grain refinement process.

* The proper conditions for evaluating the efficiency of Al-6Ti-1C master alloys to get a minimum grain size and maximum hardness are $983^{\circ} \mathrm{K}, 2$ minutes, and $1 \%$ wt for temperature, holding time, and addition level, respectively.

* The minimum grain size of aluminum and maximum hardness were $90 \mu \mathrm{m}$ and $70 \mathrm{Hv}$ respectively, that show excellent refinement of Al-6Ti-1C with the addition of smaller amounts of the new master alloy to pure aluminum.

\section{REFERENCES}

1. Shahmiri, M. and Kharrazi, Y., "The effects of gating systems on the soundness of lost foam casting (LFC) process of Al-Si alloy (A. 413.0)", International Journal of EngineeringTransactions B: Applications, Vol. 20, No. 2, (2007), 157.

2. Jenabali Jahromi, S. and Eslami, M., "Fatigue behavior of advanced spray casting 7075 aluminum alloy", International Journal of Engineering, Vol. 14, No. 4, (2001), 361.

3. Wang, Y. F. and Li, R., "Effect of temperature on the performance of Al-Ti-C metal alloys", Advanced Materials Research, Vol. 339, (2011), 291-294.

4. Li, J. G., Huang, M., Shi, Z. and Liu, D. Y., "The behavior of $\mathrm{Al}-\mathrm{Ti}-\mathrm{C}$ master alloys in grain refining of commercial and high pure aluminum", Materials Science Forum, Vol. 4 ,No. 75, (2005), 313-316.
5. Cao, J., Wang, Y. F. and Wei, C. X., "Effect of the size of powder on the microstructures and grain refining performance of Al-Ti-C alloys", Advanced Materials Research, Vol. 146, (2011), 887-890.

6. Zhao, H., Song, Y., Li ,M. and Guan, S., "Grain refining efficiency and microstructure of $\mathrm{Al}-\mathrm{Ti}-\mathrm{C}-\mathrm{Re}$ master alloy", Journal of Alloys and Compounds, Vol. 508, No. 1, (2010), 206-211.

7. Zhao, H.-L., Wang, J., Song, Y. and Guan, S.-K., "Microstructure and synthesis mechanism of Al-Ti-C-Sr master alloy", Transactions of Nonferrous Metals Society of China, Vol. 20, No. 5, (2010), 751-756.

8. Ding, H., Liu, X. and Yu, L., "Influence of zirconium on grain refining efficiency of Al-Ti-C master alloys", Journal of Materials Science ,Vol. 42, No. 23, (2007), 9817-9821.

9. Doheim, M., Omran, A., Abdel-Gwad, A. and Sayed, G., "Evaluation of Al-Ti-C master alloys as grain refiner for aluminum and its alloys", Metallurgical and Materials Transactions A, Vol. 42, No. 9, (2011), 2862-2867.

10. Zhang, B., Lu, L., Lai, M., Fang, H., Ma, H., and Li, J., "Synthesis mechanism of an Al-Ti-C grain refiner master alloy prepared by a new method", Metallurgical and Materials Transactions A, Vol. 34, No. 8, (2003), 1727-1733.

11. Zhang, Z., Watanabe, Y., Kim, I., Liu, X. and Bian, X., "Microstructure and refining performance of an Al-5ti-0.25 C refiner before and after equal-channel angular pressing", Metallurgical and Materials Transactions A, Vol. 36, No. 3, (2005), 837-844.

12. Birol, Y., "Response to thermal exposure of the mechanically alloyed $\mathrm{Al}-\mathrm{Ti} / \mathrm{C}$ powders", Journal of Materials Science, Vol. 42, No. 13, (2007), 5123-5128.

13. Xu, C. X., Liang, L. P., Lu, B. F., Zhang, J. S. and Liang, W., "Effect of C/Ti ratio and al powder size on microstructure and performance of Al-Ti-C grain refiner", Key Engineering Materials, Vol. 353, (2007), 2981-2984.

14. Gezer, B. T., Toptan, F., Daglilar, S. and Kerti, I., "Production of Al-Ti-C grain refiners with the addition of elemental carbon", Materials \& Design, Vol. 31, (2010), S30-S35.

15. Ding, H., Liu, X., Yu, L. and Zhao, G., "The influence of forming processes on the distribution and morphologies of tic in Al-Ti-C master alloys", Scripta materialia, Vol. 57, No. 7, (2007), 575-578.

16. Meena, P. C., Singh, S. and Sharma, A., "Factors influencing grain refining behavior of master alloys and their study on fading and poisoning phenomena in al and its alloys", Indian Foundry Journal, Vol. 58, No. 2, (2012), 23-31.

17. Popova, E., Brodova, I., Yablonskikh, T., Shirinkina, I., Barbin, N., Bodrova, L., Dolmatov, A., Pastukhov, E., Vatolin, N., and Chebykin, V., "Structure of Al-Ti-C master alloys", The Physics of Metals and Metallography, Vol. 111, No. 6, (2011), 579586.

18. Vinod Kumar, G., Murty, B. and Chakraborty, M., "Development of $\mathrm{Al}-\mathrm{Ti}-\mathrm{C}$ grain refiners and study of their grain refining efficiency on al and $\mathrm{Al}-7 \mathrm{Si}$ alloy", Journal of Alloys and Compounds, Vol. 396, No. 1, (2005), 143-150.

19. Wang, Z.-Q., Liu, X.-F., Liu, Y.-H ,.Zhang, J.-Y., Yu, L.-N., and Bian, X.-F., "Structural heredity of tic and its influences on refinement behaviors of Al-Ti-C master alloy", Transactions of Nonferrous Metals Society of China, Vol. 13, No. 4, (2003), 790-793.

20. Kashyap, K. and Chandrashekar, T., "Effects and mechanisms of grain refinement in aluminium alloys", Bulletin of Materials Science, Vol. 24, No. 4, (2001), 345-353. 


\section{Microstructure and Grain Refining Performance of a New Al-Ti-C RESEARCH Master Alloy

M .R. Rahimipour, M. Momeni, T. Naseri

Ceramic Department, Materials and Energy Research Center, Tehran, Iran

PAPER INFO

جكيده

\section{Paper history:}

Received 25 August 2012

Received in revised form 07 January 2013

Accepted 24 January 2013

Keywords:

Al-Ti-C Master Alloy

Grain Size

Solute Effect Theory

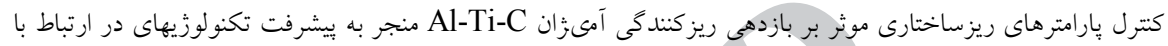

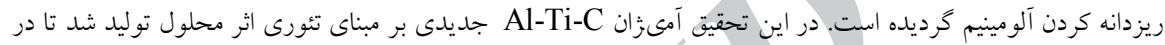

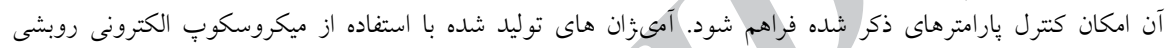

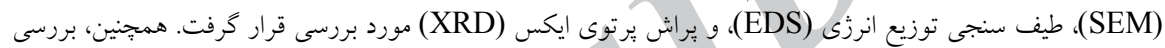

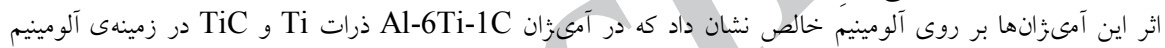

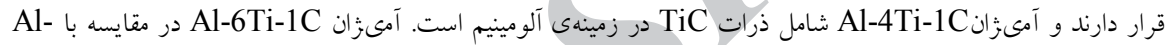

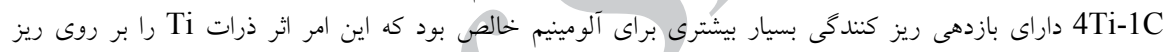

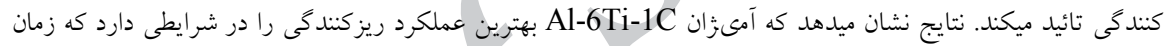

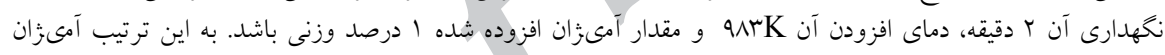

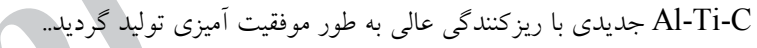




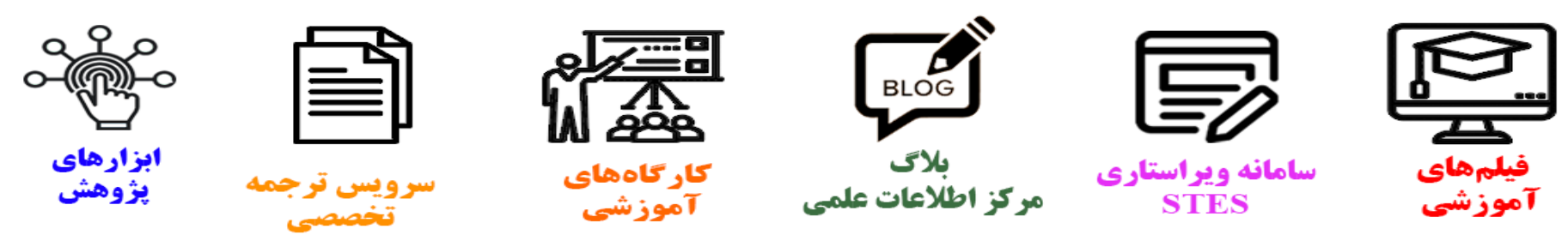

\section{(c)}

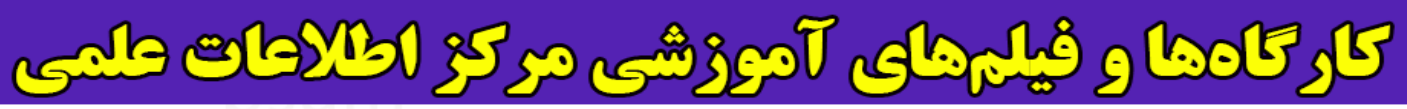
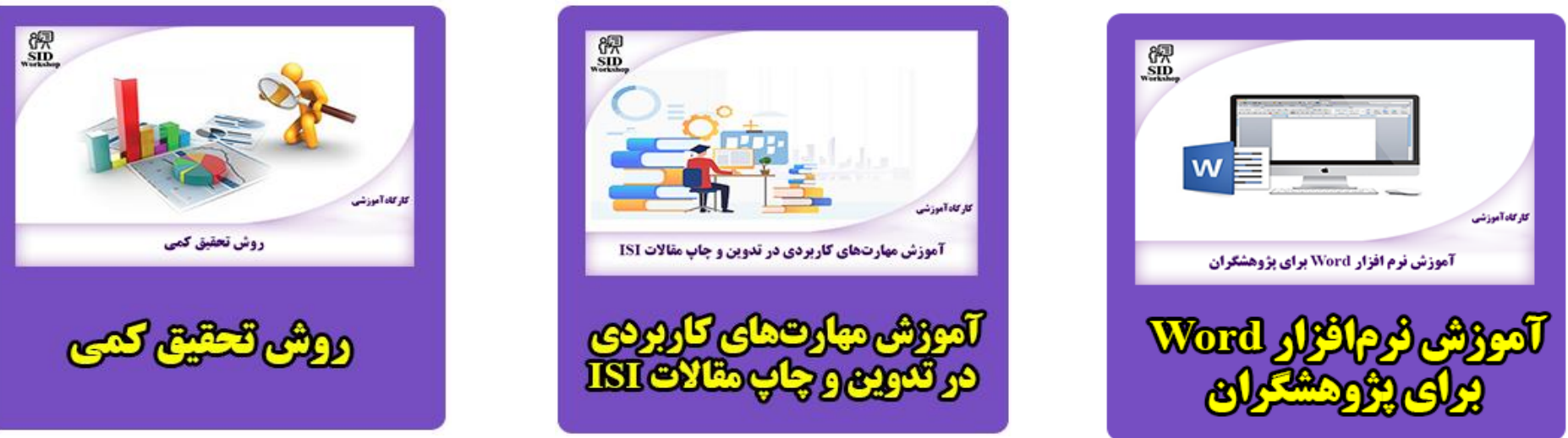